\title{
(t)
}

\section{DESENVOLVIMENTO, QUESTÃO SOCIAL E NORDESTE BRASILEIRO: CONTRADIÇÕES E TENDÊNCIAS ATUAIS}

\author{
DEVELOPMENT, SOCIAL ISSUES AND BRAZILIAN NORTHEAST: \\ CONTRADICTIONS AND CURRENT TRENDS
}

\author{
Evelyne Medeiros Pereira' ${ }^{1}$
}

\section{RESUMO}

A conjuntura mais recente do país sinaliza a permanente dialética entre mudanças e continuidades, movimento partícipe do desenvolvimento desigual e combinado do capitalismo contemporâneo que, dentre outros aspectos, tem promovido uma verdadeira "reestruturação territorial e produtiva", (re)criando distinções regionais. Refletir sobre as contradições dessa realidade na busca de identificar os principais desdobramentos na configuração da questão social e regional no Nordeste brasileiro, sem perder de vista a compreensão da totalidade social, é o objetivo do presente artigo. Para isso, desenvolvemos um estudo bibliográfico, priorizando a perspectiva críticodialética e dialogando com dados secundários.

Palavras-chave: Desenvolvimento capitalista. Formação social do Brasil. Questão social. Nordeste.

\section{ABSTRACT}

The latest situation in the country shows the permanent dialectic between change and continuity, a movement that's part of the unequal and combined development of the contemporary capitalism which, among other aspects, has been promoting a real "territorial and productive restructuring", (re) creating regional distinctions. Reflect about the contradictions of this reality in order to identify the main developments on the configuration of social

1 Docente do curso de Serviço Social do Instituto Federal de Educação, Ciência e Tecnologia do Ceará (IFCE). Membro do Núcleo de Educação, Políticas Sociais e Serviço Social (NEPSSS/IFCE). 


\section{temporollis}

and regional issues, from the Brazilian Northeast, without losing sight the understanding of the social totality, is the purpose of this article. For therefore, we developed a bibliographical study, prioritizing a critical-dialectical perspective, dialoguing with a secondary data.

Keywords: Capitalist Development. Social formation of Brazil. Social issues. Northeast.

Submetido: 16/09/2015.

Aceito: 26/11/2015.

\section{Introdução}

A realidade brasileira é atravessada por mudanças, em geral, que destacam a última década em relação a outros períodos, não podendo esse contexto ser compreendido, na sua totalidade, sem observarmos as mediações que situam o país no atual processo de mundialização e financeirização do capital. Isto além das contradições próprias do padrão de acumulação capitalista sob uma formação social particular marcada, dentre outros aspectos, pela dependência e por profundas desigualdades sociais com traços étnico-raciais, agrários, patriarcais e regionais.

Como síntese, constitui-se uma nação que atualmente ocupa o posto de sétima maior economia do mundo com o contingente de $1 \%$ dos mais ricos da população ganhando quase cem vezes mais que os $10 \%$ mais pobres (IBGE, 2012). Nesse quadro, o Nordeste brasileiro, que concentra cerca de 30\% da população nacional, possui mais da metade da pobreza no país (PNUD, 2013). Esta condição torna-se mais agravante diante da baixa qualidade dos serviços públicos e políticas sociais escassas, fragmentadas e focalizadas.

A conjuntura mais recente do país sinaliza a permanente dialética entre mudanças e continuidades, possuindo este segundo polo uma maior tônica. Porém, atentamos para o que os meios de comunicação vêm apresentando junto as demais instituições difusoras de pesquisas e índices, mesmo que no âmbito da aparência e impregnados de interesses econômicos e políticos (e não poderia ser diferente): em 2013, as matérias respectivamente intituladas "Esperança de vida cresce mais no Nordeste que no resto do Brasil" (SALLOWICZ, 2013) e "Nordeste cresce acima da média do país" (VILLELA, 2013) anunciaram o aumento considerável da expectativa de vida da população nordestina como também a tendência positiva da participação da região no Produto Interno Bruto (PIB) nacional. No mesmo ano, outra notícia, sob a chamada "Nordeste lidera crescimento no país, 
(PORTO, 2013), segundo Banco Central", divulgou também informações acerca do crescimento da região em relação às demais no trimestre compreendido entre dezembro de 2012 e fevereiro de 2013.

Em 2014, a Empresa Brasil de Comunicação (EBC) publica o texto denominado "IBGE: maior proporção de empresas de alto crescimento está no Norte e Nordeste". Em diferente perspectiva, no mesmo ano, o texto "Preconceito, eleições e a dicotomia na geografia econômica” (OSAVA, 2014), também retratou o Nordeste com maior prosperidade nos últimos anos: "[...] a economia da região mais pobre do Brasil cresce num ritmo muito superior à média nacional, que é de paralisia desde 2012 [...] das cinco regiões brasileiras, o Nordeste foi a que gerou mais empregos formais nos últimos anos." Tal situação, conforme a matéria, teria alimentado o destaque que a realidade nordestina teve nas últimas eleições presidenciais e, mais precisamente, na reeleição da candidatura representada por Dilma Roussef, do Partido dos Trabalhadores (PT), com quase $80 \%$ dos votos válidos do Nordeste do país, o que, inclusive, foi motivo de uma onda de xenofobia, especialmente nas redes sociais, desnudando a dura face da nossa "democracia".

Tais informações poderiam sinalizar tendências? Para responder a esta questão, é preciso, na busca de seus fundamentos, identificar as contradições que compõem esse quadro, contemplando seus aspectos conjunturais e estruturais. Assim, é importante observar, mesmo que o discurso do "crescimento" não sinalize, que o "desenvolvimento" tão aclamado não tem repercutido em mudanças consideráveis nas condições de vida das classes trabalhadoras e nas desigualdades sociais expressas, por exemplo, no agravamento da "questão regional" como uma particularidade da "questão social" no Brasil. Basta recorrermos a outras fontes como a entrevista de 2015, intitulada "Ainda existem dois Brasis", (TINEO, 2014, online), e a matéria denominada "Região Nordeste registra maior taxa de desocupação do país", (OLIVEIRA, 2015, online), também do mesmo ano. Isto além das demais pesquisas oficiais que nos dizem ser o Nordeste ainda a região do país com maior taxa de analfabetismo, menores índices de desenvolvimento humano entre os municípios e, portanto, ainda com presença considerável de emigração, embora em menor medida se compararmos com décadas atrás.

Dessa forma, o entendimento sobre a natureza do projeto de desenvolvimento em curso e seus principais desdobramentos para o 


\section{temporollis}

país e suas regiões, demandará, dentre outros passos, enfrentar os aparatos ideológicos, muito bem refinados, em torno do discurso do "crescimento econômico" e "desenvolvimento social/regional", o que exige um nível de aprofundamento do estudo e da análise. Diante desse cenário, somado a importância de entendermos como se articulam as esferas globais e locais da dinâmica capitalista contemporânea, a dimensão regional merece nossa atenção.

Refletir sobre as contradições dessa realidade, procurando identificar seus principais desdobramentos na configuração da "questão social" no Nordeste brasileiro, é, portanto, o objetivo do presente artigo. Para isso, desenvolvemos, de forma preliminar, um estudo bibliográfico, com explicitação de dados secundários, a fim de fundamentar nossas argumentações. É, portanto, imprescindível considerarmos os aspectos sócio históricos da realidade, as expressões e tendências do "capitalismo tardio" (MANDEL, 1982) e suas particularidades na recente conjuntura brasileira e nordestina. Isso, a nosso ver, é o ponto de partida necessário para o entendimento do papel das desigualdades regionais no padrão de acumulação vigente e hegemônico.

\section{Formação social brasileira, transformações contemporâneas e questão regional}

A sociedade brasileira é fruto e partícipe de um movimento, já descrito por Marx e Engels (1998, p.11-12), em 1848, plenamente manifestado nos dias atuais: "No lugar da tradicional autossuficiência e do isolamento das nações surge uma circulação universal, uma interdependência geral entre os países. $\mathrm{E}$ isso tanto na produção material quanto na intelectual." Trata-se da condição de existência e desenvolvimento do modo de produção capitalista: a universalização, a expansão mundial do capital como tendência:

[...] uma iluminação universal em que atuam todas as cores, e às quais modifica em sua particularidade. É um éter especial, que determina o peso específico de todas as coisas às quais põe em relevo. (MARX, 2008, p. 264).

Porém, é importante ressaltar - para evitarmos análises eurocêntricas que recorrentemente legitimam uma visão linear da história - que a forma de produção dominante exerce sua hegemonia com formas particulares, inclusive nas formações sociais onde subsistem relações pré-capitalistas, como uma "luz universal" que transforma as 
outras "cores". Daí o nível de complexidade do desenvolvimento capitalista nas diferentes sociedades, atuando como uma "unidade na diversidade". Afinal, a "sociedade produtora de mercadorias" não se desenvolve sobre uma realidade homogênea, mas está inserida, "[...] cresce e se difunde em um ambiente geográfico variado que abarca grande diversidade." (HARVEY, 2013, p.526). Mesmo que o movimento ampliado do capital tendencialmente aponte para a destruição das fronteiras regionais, dos "preconceitos nacionais" e demais barreiras territoriais ao desenvolvimento das forças produtivas ${ }^{2}$ e outras necessidades materiais e espirituais de expansão capitalista, encontra, no seu próprio modo de ser, barreiras que demandam a produção de novas formas de "diferenciação geográfica", "novas distinções em velhos modos”.

Nesse sentido, Löwy (1995, p.73-74) sinaliza a magnitude da contribuição dada por Leon Trotsky à perspectiva marxista através da sua "teoria do desenvolvimento desigual e combinado", "[...] uma

2 O debate em torno da questão do desenvolvimento demanda uma análise mais apurada acerca do desenvolvimento das forças produtivas na tradição marxiana e marxista. Sobre isso, ressaltamos que, na sociedade capitalista, tal desenvolvimento é a alavanca propulsora da alienação humana ou, em outras palavras, do "fetichismo da mercadoria" (MARX, 1983). Porém, é importante observar que o desenvolvimento das forças produtivas ocorre em permanente e complexa articulação com as relações sociais, de produção, variando ao longo da história, o que tornou possível a constituição como também o colapso dos modos de produção já existentes, tal como nos sinaliza Marx (2008, p.45): "Em uma certa etapa de seu desenvolvimento, as forças produtivas materiais da sociedade entram em contradição com as relações de produção existentes, ou, o que não é mais que sua expressão jurídica, com as relações de propriedade no seio das quais elas se haviam desenvolvido até então. De formas evolutivas das forças produtivas que eram, essas relações convertem-se em entraves. Abre-se, então, uma época de revolução social." Nesta direção, Lukács (2008, p. 161-162) nos aponta as contradições postas na histórica (e ontológica) relação entre processo de trabalho, forças produtivas, necessidades e capacidades humanas: "[...] o desenvolvimento das forças produtivas provoca diretamente um crescimento das capacidades humanas, mas pode, ao mesmo tempo e no mesmo processo, sacrificar os indivíduos (classes inteiras)". Por isso, o “[...] desenvolvimento das forças produtivas é necessariamente também o desenvolvimento das capacidades humanas, mas - e aqui emerge plasticamente o problema da alienação - o desenvolvimento das capacidades humanas não produz, obrigatoriamente, aquele da personalidade humana."

3 "A desigualdade do ritmo, que é a lei mais geral do processus histórico, evidencia-se com maior e complexidade nos destinos dos países atrasados. Sob o chicote das necessidades externas, a vida retardatária vê-se na contingência de avançar aos saltos. Desta lei universal da desigualdade dos ritmos decorre outra lei que, por falta de denominação apropriada, chamaremos de lei do desenvolvimento combinado, que significa aproximação das diversas etapas, combinação das fases diferenciadas, 


\section{temporolis}

tentativa de [...] dar conta da lógica das contradições econômicas e sociais dos países de capitalismo periférico ou dominados pelo imperialismo."

É, portanto, sob esse movimento histórico que se consolidam as bases da formação social brasileira. Esta, segundo Prado Júnior (2008), foi particularizada por intermédio do processo de colonização, revelando como o capitalismo no país articula permanentemente aspectos considerados "avançados" e "retrógrados". Este traço tem sido trabalhado equivocadamente nas análises dualistas sustentadas, por exemplo, em conceitos como o de "subdesenvolvimento", associado a existência de uma "formação histórico-econômica singular" constituída por dois polos opostos - o "atrasado" e o "moderno". Conforme Oliveira (2013, p.32), essa concepção "não se sustenta como singularidade", pois "esse tipo de dualidade é encontrável não apenas em quase todos os sistemas, como em quase todos os períodos". Daí ser meramente formal a oposição entre o arcaico e o moderno. Na verdade, o que existe é uma verdadeira "[...] simbiose [... ] uma unidade de contrários, em que o chamado 'moderno' cresce e se alimenta da existência do 'atrasado'."

A colonização foi, nessa direção, fundamental para a "acumulação originária" do capital nos países centrais, expressão de uma "nova ordem que é a do mundo moderno" (PRADO JR., 2008). Oliveira (2013, p. 33) ainda reforça: "[...] as economias pré-industriais da América Latina foram criadas pela expansão do capitalismo mundial, como uma reserva de acumulação primitiva do sistema global", o que deslegitima a concepção daqueles(as) que acreditam na existência de um "subdesenvolvimento" que necessita ser superado por intermédio do próprio desenvolvimento capitalista, quando este, na verdade, com seu caráter desigual e combinado, aprofunda a dependência.

Daí nasce o Brasil, nação voltada "para fora", como uma vasta empresa comercial, tendo como base três principais pilares: a grande propriedade (plantation), a monocultura e o trabalho escravo.

Esse lastro, para Prado Jr. (2008), é central na conformação dos setores "orgânicos" e das classes fundamentais da sociedade brasileira, sendo a "questão agrária", enquanto particularidade da "questão social”, uma marca irremediável das relações sociais expres-

amálgama das formas arcaicas com as mais modernas" (TROTSKY, 1977, p.25). 


\section{temporolis}

sa no pauperismo no campo e nas cidades ${ }^{4}$.

O embrião do capitalismo no país se processou, nas palavras de Gorender (1982, p.09), por intermédio do "[...] escravismo colonial [... tendo este como a fonte da própria acumulação". No entanto, o "agente organizador" dessa acumulação não deixou de ser a burguesia, "associada" ao grande capital (IANNI, 2004) e destituída de um projeto político de orientação democrática e de soberania nacional, mediante arranjos de cúpula com setores oligárquicos, sem por isso realizar "[...] uma 'revolução democrático-burguesa' ou de 'libertação nacional' segundo o modelo jacobino." (IAMAMOTO, 2007, p.132). O que houve foi uma verdadeira "revolução passiva", demonstrando a debilidade histórica da democracia e o predomínio das relações autoritárias, aprofundando os laços e mecanismos de dependência e restauração (GRAMSCl, 2006). 5

Vale ressaltar que a garantia da hegemonia burguesa deu-se mediante a exploração desenfreada das classes trabalhadoras, por mecanismos que viabilizam a mais-valia absoluta e relativa, combinando "[...] duas táticas calculistas por parte do patronato: a do paternalismo e a da repressão" (GORENDER, 1982, p.49), o que revela o caráter autocrático do Estado em meio a uma sociedade atravessada pela "modernização conservadora" (FERNANDES, 2006). A conformação de alianças políticas que mantém uma rígida estrutura de poder, incide violentamente sob a relação de forças sociais no país até os nossos dias. O que nos faz inevitavelmente lembrar da velha, porém atual,

4 Para Marx (2008, p.748), “[...] quanto maior esse exército de reserva em relação ao exército ativo, tanto maior a massa da superpopulação consolidada, cuja miséria está na razão inversa do suplício de seu trabalho. $\mathrm{E}$, ainda, quanto maiores essa camada de lázaros da classe trabalhadora e o exército industrial de reserva, tanto maior, usando-se a terminologia oficial, o pauperismo. Esta é a lei geral, absoluta, da acumulação capitalista". Esse processo é o provedor da 'questão social', apreendida como o conjunto das expressões das desigualdades da sociedade capitalista madura. Questão social que, sendo desigualdade é também rebeldia, por envolver sujeitos que vivenciam as desigualdades e a ela resistem e se opõem." (IAMAMOTO, 2004, p. 27-28).

5 “[...] o fato histórico da ausência de uma iniciativa popular unitária no desenvolvimento da história italiana, bem como o fato de que o desenvolvimento se verificou como reação das classes dominantes ao subversivismo esporádico, elementar, não orgânico, das massas populares, através de 'restaurações' que acolheram uma certa parte das exigências que vinham de baixo; trata-se, portanto, de "restaurações progressistas', ou 'revoluções restaurações', ou, ainda, 'revoluções passivas'." (GRAMSCI, 2006, p. 393). 


\section{temporollis}

frase dita no contexto do Risorgimento italiano: "Algo deve mudar para que tudo continue como está" ou, em outras palavras, "Tudo deve mudar para que tudo fique como está."

Em meio a dialética entre modernização e conservadorismo, "internacionalização" e "particularismos nacionais e regionais" (MÉSZÁROS, 2002), é importante destacar um aspecto permanentemente pulsante na formação sócio histórica brasileira: as desigualdades regionais. Estas, partícipes do movimento de concentração e centralização do capital, são resultantes das contradições do modo de produção vigente, "[...] sinal de uma redefinição da divisão regional do trabalho no conjunto do território nacional." (OLIVEIRA, 1981).

Harvey (2013, p.527) nos lembra a importância da relação entre tempo e espaço na produção e circulação capitalista. Assim, a maisvalia (ou o mais-valor) deve ser produzida e realizada em um período de tempo socialmente necessário, dadas as circunstâncias históricas de cada época. "Se é necessário tempo para superar o espaço, o maisvalor deve também ser produzido e realizado dentro de um determinado domínio geográfico." Eis a base para o que o autor denomina de "desenvolvimento geográfico desigual no capitalismo". Na busca de superar as fronteiras de tempo, espaço e de "distinções regionais", o desenvolvimento capitalista estabelece outras tantas barreiras espaciais, diferenciações geográficas e regionais. Fruto desse processo, ocorre a "regionalização da lutas de classes e entre facções" como também o adensamento da "questão social" na sua dimensão regional, expressa pela intensificação da divisão internacional do trabalho, da exploração do trabalho por intermédio da "reestruturação territorial e produtiva" - que afeta decisivamente as condições econômicas, políticas e ideológicas dos(as) trabalhadores(as) - e dos diversos conflitos de base territorial que promovem uma onda migratória cada vez mais pulsante nos dias de hoje. ${ }^{6}$

Esse processo ocorre contraditoriamente no período identificado por Chesnais (1996) de "mundialização" em que o "[...] capital expande sua face financeira integrando grupos industriais associados às instituições financeiras que passam a comandar o conjunto da acumulação." (IAMAMOTO, 2007, p.21) Trata-se da maturação do circuito

6 Em relação às migrações internacionais, de acordo com a ONU, o mundo possui atualmente cerca de 232 milhões de migrantes, o que corresponde a 3,2\% da população. (ONUBR, 2013). 


\section{tempordils}

intrínseco ao padrão de acumulação capitalista, já analisado por Marx (1983) desde o século XIX, apresentando como centro o chamado "capital portador de juros". O desencadeamento de uma crise sem proporções - em um "[...] continuum depressivo, que exibe as características de uma crise cumulativa, endêmica, mais ou menos permanente e crônica, com a perspectiva última de uma crise estrutural cada vez mais profunda e acentuada" (MÉSZÁROS, 2002, p.697) - cria um ambiente propício no país para o avanço de formas "inovadoras" de expansão do capital. O mecanismo de "inflação do valor dos ativos", de "formação de capital fictício", associado ao "serviço da dívida pública e as políticas monetárias", viabiliza as transferências efetivas de riqueza para a esfera financeira. E isso só é possível pela permanente presença dos Estados Nacionais.

Nesse quadro, os fatores de hierarquização entre as nações e regiões são acentuados, ao mesmo tempo, redesenhados, o que promove também o adensamento da dependência em países como o Brasil. "O abismo que separa os países participantes, mesmo que marginalmente, da dominação econômica e política do capital monetário rentista, daqueles que sofrem essa dominação, alargou-se ainda mais." (CHESNAIS, 1996, p.15-19)

Daí a importância de sinalizar a função cada vez mais ativa que assume o fundo público - parcela significativa do trabalho necessário e da mais-valia socialmente produzida capitaneada pelo aparato estatal - nas políticas macroeconômicas, valorizando capitais com a transferência de um montante considerável de recursos públicos sob a forma de juros e amortização da dívida pública para a esfera financeira. Tais circunstâncias demonstram a vitalidade do pensamento marxiano, quando situa a dívida pública como um importante "alavanca da acumulação primitiva". Sobre isto, conforme o documento "Os números da Dívida", o valor do orçamento público destinado à dívida pública no Brasil, em 2012, correspondia a 47,19\% de todo o orçamento e equivalia a mais de 1 trilhão de reais. Já as informações de 2014 nos dizem que o montante da dívida cresceu em aproximadamente 3,43\%, o que corresponde a mais de 2 trilhões de reais. (FATORELLI; ÁVILA, 2015).

Com isso, os ajustes e as "contrarreformas" (BEHRING, 2008) implementadas no Brasil, com maior intensidade a partir da década de 1990, representam muito mais que "uma programática econômica", expressam uma redefinição mundial do campo político-institucional e, em face da desigualdade crescente, "[...] situa a figura do pobre no 


\section{temporollis}

centro de políticas focalizadas de assistência. Ocorre, então, um deslocamento da função assistencial, que se torna um instrumento essencial de legitimação do Estado." (PAULO NETTO, 2007, p.150) Este quadro, que não é essencialmente uma novidade para a hegemonia do capital, condiciona um "formato" para as políticas sociais que devem:

[...] possibilitar a 'inserção' da força de trabalho no mundo das finanças [...]. A modelagem dessas novas mercadorias exige do Estado a redução das políticas sociais como equipamentos públicos e sua transformação em 'direitos monetarizados' operados nos mercados bancário-financeiros. (GRANEMANN, 2007, p.58-59).

Os reflexos desse contexto de agravamento das "tendências contrapostas e contraditórias" do desenvolvimento capitalista incidem sobre a realidade brasileira particularmente nos últimos anos. $\mathrm{Na}$ reconfiguração de barreiras espaciais e distinções regionais, o Nordeste brasileiro continua cumprindo um papel central no âmbito da divisão regional do trabalho, ofertando mão de obra abundante e com um menor custo e especialização em relação a outras regiões onde se concentram as riquezas produzidas no país.?

Porém, é importante observar que a conformação da realidade nordestina historicamente recompõe os aspectos que, na verdade, são próprios da formação social do país: as oligarquias tradicionais "[...] tiveram influência na reprodução histórica de uma sociedade baseada no princípio da intocabilidade do poder político e econômico. Esse processo demarcou a construção social do Nordeste e teve no Estado um protagonista [...] mudando pouco para não mudar o todo." (PEREIRA JR., 2012, p. 196)

Com isso, identificar as atuais expressões da questão regional na realidade brasileira nos marcos do desenvolvimento (desigual) em curso, se apresenta, nesse momento, como desafio central.

7 Conforme relatórios de pesquisas desenvolvidas pelo IBGE e pela OIT no ano de 2011, as regiões Norte e Nordeste foram identificadas como aquelas que apresentam menores taxas de formalidade nas relações de trabalho no país. Além disso, em geral, os trabalhadores expostos às condições análogas ao trabalho escravo possuem, na sua maioria, naturalidade nordestina. Tal quadro não sofreu consideráveis alterações. (NITAHARA, 2014). 


\section{tempordilis}

\section{Conjuntura brasileira e o Nordeste hoje}

Em meio à expansão da especulação e do capital financeiro em esfera mundial, priorizando uma política monetária e cambial conservadora com taxas de juros elevadas, controle inflacionário e garantia do superávit primário, nos anos 2000, especialmente a partir de 2003, houve uma retomada do papel do Estado em impulsionar o crescimento econômico no país sob a insígnia do "desenvolvimento social, econômico e regional”. Para alguns(as) analistas, sob uma nova direção política, a "roda da economia" tomava um outro impulso, começava a se movimentar após anos de estagnação, especialmente nos setores de energia, de saneamento e habitação popular e das ferrovias, aeroportos, portos, estradas, tecnologias, entre outros, com impactos regionais e em âmbito local. Para outros(as), trata-se, na verdade, de uma "[...] nova fase do desenvolvimento capitalista inaugurada nos governos do Partido dos Trabalhadores (PT)" que terá como uma de suas principais marcas o retorno da "ideologia desenvolvimentista" (CASTELO, 2012, p. 614).

Além de certa recuperação do emprego, redução da informalidade, recomposição do salário-mínimo e elevação do Produto Interno Bruto (PIB) - que em 2002 correspondia a 6,9\% e em 2009 subiu para o montante de 9,3\% (IPEA, 2010, p. 20) - algumas iniciativas no âmbito das políticas, com viés mais focalizado e compensatório, de transferência de renda às famílias que se encontram em situação de "extrema pobreza", ganharam bastante notoriedade, ocasionando desdobramentos, a exemplo do alargamento da capacidade de consumo de segmentos mais subalternizados da sociedade, através da inclusão bancária e creditícia. Sobre isso, vale destacar que o Programa Bolsa Família, "[...] com cobertura nacional de 1,15 milhão de famílias em outubro de 2003, atingiu 12,37 milhões em dezembro de 2009" e cerca de 14 milhões em 2014.

Para Pochmann (2013, p.151), "[...] com a complementação de renda pelas transferências, o Brasil registra 18,7 milhões de pessoas com até um quarto de salário-mínimo mensal." Tais circunstâncias, para o autor, fizeram com que o quadro geral da pobreza no país tendencialmente apresente uma redução de 30\% desde 2003. Esse processo foi acompanhado por outras medidas no campo das políticas sociais, como a implementação da Política Nacional de Assistência Social (PNAS) e do Sistema Único da Assistência Social (SUAS), desde 2004. 


\section{temporollis}

Segundo o Instituto de Pesquisa Econômica Aplicada (IPEA. 2010, p. 23), houve uma considerável retomada nos investimentos públicos especialmente a partir do ano de 2005, totalizando cerca de $\mathrm{R} \$ 300$ bilhões até 2009, "[...] com destaque para a infraestrutura de petróleo e gás, energia hidroelétrica e construção civil." Em relação a participação do rendimento do trabalho na renda nacional, de acordo com Pochmann (2013, p.146), houve um movimento de recuperação nos anos 2000, subindo 14,8\% de 2004 a 2010. "Noutras palavras, há uma ampliação na taxa de ocupação em relação ao total da força de trabalho (isto é, uma queda do desemprego) e na formalização dos empregos da mão de obra, com a queda na pobreza absoluta".

No âmbito das relações internacionais, algumas destacadas ações de fortalecimento do Mercado Comum do Sul (Mercosul), de inserção do Brasil na Comunidade dos Estados Latinoamericanos (CELAC) e na União das Nações Sul-Americanas (UNASUL) foram desenvolvidas. Nesse quadro, o Brasil tem assumido cada vez mais um papel central na oferta internacional de commodities, intensificando o agronegócio no país e a "reprimarização" da pauta de exportações.

Estaríamos falando, portanto, de uma reedição da política desenvolvimentista que ocorreu no Brasil entre 1930 a 1980? Chegar a esta conclusão, a nosso ver, nos traz equívocos e não nos permite entender o real processo em curso, tendo em vista que esse quadro geral, até então apresentado por nós, possui um conjunto de características que permite identificar a continuidade da hegemonia neoliberal, especialmente na realidade mais atual de estagnação de crescimento, avanço de pautas conservadoras e ajuste fiscal com cortes orçamentários especialmente nas políticas sociais.

Para Boito Jr (2012, p.07), a última década é caracterizada por um contexto em que a relação de forças sociais favoreceu a formação de uma "frente neodesenvolvimentista", gelatinosa e heterodoxa, que viabilizou governos de "composição de classes" em torno de um projeto de desenvolvimento possível nos marcos do modelo neoliberal. Nesta perspectiva, tomando também como base as análises de Alves (2013, online), podemos entender que, embora "o projeto burguês do neodesenvolvimentismo" tenha nascido "[...] no bojo da crise do neoliberalismo [...], ele não poderia ser mera continuidade do projeto I (projeto neoliberal), oriundo da década de 1990, sob pena de ir à ruina." 


\section{tempordils}

Sob o semblante da afirmação periférica do "reformismo impotente" (ARCARY, 2014), o que houve, segundo o autor, foi a construção das bases para um novo patamar de acumulação do capital nas condições dadas pela crise estrutural, demandando com maior veemência a função reguladora do Estado investidor para "[...] financiar e constituir grandes corporações de capital privado nacional com a capacidade competitiva no mercado mundial" (ALVES, 2013, online). Daí a ênfase no papel do fundo público via Banco Nacional de Desenvolvimento Econômico e Social (BNDES) e fundos de pensões de estatais, viabilizando grandes obras. Isto, porém, não deixou imune o país da crise, nem poderia.

Diante dessa realidade, atentamos para as particularidades regionais, mais precisamente para a necessidade de compreender como o Nordeste se insere no padrão de reprodução capitalista e no projeto de desenvolvimento em curso. Isso tendo em vista que no período de 2003 a 2010 as estatísticas oficiais revelam uma taxa de crescimento da economia da região de $4,9 \%$, ou seja, mais elevada que a média nacional que foi de 4,4\% (ARAÚJO, 2013, p.164). Houve também uma liderança, junto a região Norte, do crescimento do consumo ao longo dos anos 2000, conforme Araújo (2013). Além disso, ressalta que a elevação real do salário-mínimo teve impacto mais forte na realidade nordestina, onde "[...] 45\% dos ocupados recebem até um salário-mínimo - bem acima da média nacional que é de $26 \%$ [... ] entre 2003 e 2009 o valor do rendimento médio" das famílias da referida região "[...] cresceu 5,4\% ao ano, quando a média brasileira foi de 3,5\%, e no Sudeste essa taxa foi de apenas 2,9\%." (p. 162).

Já sobre o Programa Bolsa Família, levando em consideração que as desigualdades regionais favorecem a divisão entre pobres e ricos territorialmente, como o Nordeste possui "[...] mais da metade da população muito pobre do país, capta $55 \%$ dos recursos desse programa", o que tem influenciado diretamente tanto nas condições de vida dessa parcela populacional como na dinâmica econômica e territorial do interior nordestino com a constituição das chamadas "cidades médias", dinamizando o comércio e gerando "[...] nos pequenos municípios um impacto econômico num movimento virtuoso que estimula a crescer." (ARAÚJO, 2013, p. 162). Ainda ressaltamos que algumas ações, desenvolvidas na última década, vinculadas a outras políticas, a exemplo da educação profissional e superior, com uma tendência a expansão e a interiorização de unidades de ensino, mesmo diante de todas as adversidades relativas às condições de trabalho e funciona- 


\title{
temporollis
}

mento, têm também adensado impactos significativos na vida cultural, política e econômica dessas cidades. ${ }^{8}$

Em relação ao investimento público, especialmente via BNDES, que passaram de 2,73 bilhões, em 2000, para 5,4 bilhões de reais, em 2007 , aos programas e projetos voltados para infraestrutura e produção industrial, as maiores parcelas, pelo menos até 2009, foram destinadas aos estados nordestinos através, por exemplo, da construção e implantação da Transposição do Rio São Francisco; da Transnordestina (estrada de ferro entre os estados de Pernambuco, Piauí e Ceará); dos Complexos Industriais e Portuários no Ceará (Pecém); e, em Pernambuco (Suape), com estaleiros e refinaria da Petrobrás e planos de montagem de siderúrgica, laminadora e montadora de automóveis da Fiat.

\begin{abstract}
Um dado novo, revelado com as recentes transformações sentidas pelo Nordeste, aponta para a inserção de uma nova política macroeconômica a atingir intensamente a região. Esse dado tem a ver com a relativa mudança de rumo assumida pelo governo Lula, que, apesar de garantir a manutenção de inúmeros acordos firmados com os capitais produtivos e financeiros internacionais, vem, paradoxalmente, implementando ações econômicas com certa influência nacional-desenvolvimentista no território nacional. Isso possivelmente representa o nascimento de uma nova fase na evolução econômica e industrial nordestina [...]. Segundo dados do Banco do Nordeste do Brasil (BNB, 2008), os empreendimentos privados financiados pela instituição passaram de 222 milhões de reais, em 2002, para 5,3 bilhões, em 2007 [... ]. Outros indicativos positivos somam-se a esses números, em especial a ampliação das exportações, que passaram de 3,3 bilhões de reais em 1999 para 13 bilhões em 2007 (MIDIC, 2010a), e os dados do PIB, que avançou de 191,5 bilhões de reais em 2002 para 347,7 bilhões em 2007 (IBGE, 2009) (PEREIRA JR, 2012, p. 221).
\end{abstract}

Essa dinâmica é acompanhada também por um conjunto de incentivos por parte dos governos federal e estaduais, que atraiu setores industriais (de transformação, calçadista, alimentos e bebidas, etc.) e da construção civil através de programas ("Minha Casa Minha Vida", Aceleração do Crescimento/AC, entre outras ações), isenções fiscais e oferta de mão de obra mais barata em relação a outras re-

8 Ver em PEREIRA, HOLANDA; SOARES et al., 2015. 
giões do país. Isto tendo em vista a margem salarial dos(as) trabalhadores(as) que vivem nos estados do Nordeste e ganham em torno de um salário-mínimo, quando essa média chega a triplicar em outras regiões do país, principalmente Sul e Sudeste. Todo esse processo viabilizou, conforme o IPEA (2010), uma maior dinamização do mercado de trabalho com a geração de empregos formais como também de Arranjos Produtivos Locais (APLs), além do aumento da movimentação dos serviços, multiplicando o crédito e elevando o consumo.

Nesse quadro, grupos empresariais, como os bancos Itaú e Bradesco e as empreiteiras Odebrecht, Andrade Gutierrez e Camargo Correa, além daqueles que atuam mais diretamente no agronegócio, como a Suzano papel e celulose, antiga Aracruz Celulose, ganharam bastante destaque, inclusive, nas estratégias empreendidas hoje no âmbito das "políticas sociais". Sobre isto, podemos citar o movimento "Todos pela Educação" que nasceu em 2006 a partir da articulação de um conjunto de organizações vinculadas diretamente à importantes corporações com o intuito de incidir sobre as diretrizes das políticas educacionais no país.

A elevação do PIB que, segundo Grabois (2014, online), quadruplicou de 2003 para 2013, com o destaque para algumas regiões como o Nordeste; o incentivo dado a "descentralização territorial" na implantação de polos industriais, a exemplo da indústria naval, "renascida na esteira do petróleo"; o crescimento do número de trabalhadores(as) da indústria, passando de 4,8 milhões, em 2003, para quase 13 milhões, em 2013, na indústria de transformação, e, de 2 milhões para 6 milhões na construção civil no mesmo período; são aspectos que incidiram nos últimos processos eleitorais, influenciando na base de sustentação dos governos e no seu projeto de desenvolvimento. $O$ autor destaca que "[...] a incorporação de trabalhadores e de regiões ao movimento do capital produziu mudanças perceptíveis, mas que ainda não foram absorvidas pelas classes em luta."

Por outro lado, vivenciamos um permanente e contínuo quadro de desigualdade regional que ainda faz do Nordeste um destaque em baixos Índices de Desenvolvimento Humano (IDH), elevados indicadores de analfabetismo, mortalidade infantil e pobreza, em geral. Em 2010, por exemplo, a "[...] taxa de analfabetismo das pessoas de dez anos ou mais para o país era de $9 \%$, mas a do Nordeste era de 17,6\%, enquanto a do Sul era de 4,7\%." (ARAúJO, 2013, p.171). Assim, 


\section{temporollis}

[...] o recente crescimento econômico não altera no mesmo ritmo as condições de vida de milhares de pessoas que continuam atingidas pela exclusão e pobreza, em especial nas grandes áreas metropolitanas e no sertão semiárido [... ] a distribuição de renda, de terras e de oportunidades continua desigual no Nordeste, e o baixo índice de Desenvolvimento Humano (IDH), ao lado da concentração espacial da indústria e das atividades econômicas de destaque, ainda é uma realidade (PEREIRA JR, 2012, p. 225).

Para Pochmann (2013, p.152), os estados mais ricos "[...] absorvem a maior parte do fundo público comprometido com as transferências monetárias", sendo incorporado pela região Sudeste " $50 \%$ do total dos recursos anualmente comprometidos com as transferências previdenciárias e assistenciais da seguridade social". Esse quadro revela também a ausência de avanços substanciais nas políticas voltadas para enfrentar as expressões da "questão social" em âmbito regional, para além de ações pontuais como o Fundo Constitucional de Financiamento do Nordeste (FNE), criado ainda na década de 1980 e de cunho mais assistencial.

É preciso entender quais os setores da sociedade que efetivamente vêm se apropriando da imensa parcela dos recursos públicos e das riquezas produzidas pelo maior crescimento econômico na última década. Sobre isso, destacamos novamente o papel do agronegócio e dos grandes projetos subsidiados pelo BNDES que, nos últimos anos, disponibilizou por volta de um terço do total dos recursos "[...] para somente dez grandes grupos econômicos privados em processo de concentração e fusão." (POCHMANN, 2013, p.152). Considerando as empresas estatais, "[...] chega-se ao resultado de quase dois terços do total dos recursos desembolsados pelo banco público para apenas doze grandes corporações nacionais privadas e estatais." Enquanto isso, a acentuada atenção dada às ações que, para Mota (2012), promovem uma espécie de "assistencialização" das políticas sociais, na verdade, não vem correspondendo a redução da concentração de renda e do fosso entre ricos e pobres no país. A respeito disso, o Brasil ainda assume $79^{a}$ posição no ranking de países reconhecidos pela Organização das Nações Unidas (ONU) em relação ao Índice de Desenvolvimento Humano (IDH).

Esse processo é acompanhado pelo congelamento salarial de setores médios da classe trabalhadora, a exemplo do funcionalismo público, além do escasso investimento em políticas mais estruturan- 
tes, imprimindo um teor (neo)liberalizante às ações, a exemplo da criação da Empresa Brasileira de Serviços Hospitalares (EBSERH), da implantação previdência complementar através da Fundação da Previdência Complementar do Serviço Público Federal (FUNPRESP), da concessão privada de aeroportos e portos e das demais ações do "pacote" de ajuste fiscal que já indica o esgotamento tanto das medidas de crescimento econômico, possíveis na década anterior, como da própria "frente neodesenvolvimentista".

Além disso, a recomposição da classe trabalhadora e a inserção de jovens, na maioria das vezes de forma precarizada, no mundo do trabalho e na educação superior, constituindo um "novo" segmento social, denominado por Braga (2012) de "precariado"; somada a precarização de serviços públicos, como de transporte coletivo e educação; e, a conturbada vida urbana nos grandes centros, intensificam as contradições no seio do bloco de poder, ensejando um cenário de lutas, greves e protestos que caracterizam a realidade mais recente do país (DIEESE, 2013). Porém, é importante lembrar que "[...] sempre que há um avanço político de forças populares [... ] as classes dominantes, mesmo débeis, juntam as suas forças para garantir e fortalecer o Estado burguês", buscando "criar ou refazer os blocos de poder". (IANNI, 2004, p. 239).

Sobre isso, observamos, por um lado, a ascensão de setores mais conservadores, muitos advindos de segmentos médios tradicionais, com a intenção de canalizar a insatisfação popular para um caminho que intensifique o estigma e a desqualificação dos setores de esquerda e das diversas organizações políticas dos(as) trabalhadores(as) no país, atribuindo a estas - representadas no senso comum pelo PT - a responsabilidade de ameaçar a democracia no país. Essas condições, garantidas também pelo monopólio dos meios de comunicação, contribuem, decisivamente, para a descrença e desmobilização das forças políticas que podem ampliar o poder de influência e de conquistas das classes trabalhadoras, (re)pondo temas centrais na opinião pública, corriqueiramente presentes no parlamento, tais como: restrição ainda maior de direitos sociais, a exemplo da previdência social, e retirada de direitos trabalhistas com o incentivo às terceirizações; redução da maioridade penal; rejeição à descriminalização do aborto; contestação à legalização das drogas; questionamento do casamento homoafetivo; intensificação do estigma do pobre e dos programas sociais via crítica conservadora; criminalização dos movimentos e lutas populares; ascensão de manifestações pró-dita- 


\section{temporollis}

dura militar, de caráter xenofóbico e racista, inclusive intensificados no último pleito eleitoral contra a população nordestina.

Ganha maior notoriedade a presença de mecanismos de controle e criminalização, conformando o que alguns analistas chamam de "militarização da sociedade", com o "avanço do Estado penal" (WACQUANT, 2013) e das políticas punitivas que, vale lembrar, possuem teor secular e são aspectos permanentes da construção e manutenção de hegemonia, especialmente em realidades com frágeis instituições democráticas. Basta lembrar o genocídio indígena, a escravidão, as ditaduras, a violência no campo, o encarceramento em massa, o extermínio de jovens negros e pobres, entre outros, como medidas de enfrentamento à "questão social".

Conforme dados do Departamento Intersindical de Assessoria Parlamentar (DIAP), "[...] dos 594 parlamentares eleitos em 2010, 273 são empresários, 160 compõem a bancada ruralista, 66 são da bancada evangélica e apenas 91 parlamentares são considerados representantes dos trabalhadores." (FERREIRA, 2014, online). No último pleito eleitoral, as forças conservadoras ganharam ainda mais adesão no Congresso Nacional. Esta realidade, somada a outros aspectos, vem adensando a insatisfação e o descrédito aos mecanismos da democracia representativa no país.

Essa conjuntura reforça e renova, de forma mais complexa, uma característica presente em toda a história da formação brasileira: a restrição de direitos e a debilidade democrática, demonstrando que as mudanças transcorridas até hoje possuem muito mais elementos de "restauração" (GRAMSCI, 2006) que de ruptura, sendo uma ou outra ampliada ou retraída a partir das contradições presentes no seio do próprio desenvolvimento capitalista, dependendo fundamentalmente da ação das classes sociais sob tais contradições.

Por fim, nos remetemos às palavras de Alves (2013, online) que considera coerente conceber o projeto de desenvolvimento vigente como "[...] incapaz de alterar qualitativamente, a natureza da ordem oligárquica burguesa historicamente consolidada no Brasil de hoje, mais do que nunca, pelo poder dos grandes grupos econômicos beneficiários da reorganização do capitalismo brasileiro dos últimos vinte anos."

As reformas estruturais continuam sem avanço, tais como a 


\section{tempordils}

reforma agrária, urbana, tributária e política, o que demonstra os limites do "desenvolvimento" em curso no Brasil, da sua (in)capacidade de dar resposta às necessidades sociais. A possibilidade de romper $\mathrm{o}$ "cerco" posto hoje às classes trabalhadoras certamente dependerá, dentre outros fatores, do nível de organização, unidade na(s) bandeira(s) política(s) e reivindicações econômicas, além da capacidade de pressão social que estabeleça uma nova correlação de forças.

Enquanto isso, a crônica cotidiana composta por diversas trajetórias de vida e trabalho daqueles(as) que sofrem violentamente os efeitos da "questão regional" permanece presente, embora de forma reconfigurada, como marca intransponível nos marcos do desenvolvimento capitalista no Brasil e no mundo. Afinal, os meios para suprimir as barreiras espaciais e as distinções regionais, que limitam o atual padrão de acumulação, envolvem a produção de "[...] novas diferenciações geográficas que criam novas barreiras espaciais a serem superadas. A organização geográfica do capitalismo internaliza as contradições dentro da forma de valor. É isso que quer dizer o conceito do inevitável desenvolvimento desigual do capitalismo." (HARVEY, 2013, p.528).

\section{Considerações finais}

Partindo da compreensão de totalidade, com o intuito de não reproduzir análises reducionistas, levando em consideração que "[...] o conhecimento do concreto opera-se envolvendo universalidade, singularidade e particularidade" (PAULO NETTO, 2011, p. 45), identificamos que a realidade brasileira é atrelada substancialmente a uma forma particular de desenvolvimento "desigual e combinado" do modo de produção capitalista, "[...] no sentido da reaproximação das diversas etapas, da combinação das fases distintas, da amálgama de formas arcaicas com as mais modernas." (TROTSKY, 1977, p. 25). Para entendê-la, contudo, é fundamental conceber o seu caráter histórico de dependência.

Nesse sentido, sob as condições de uma fase capitalista, imperialista, que pesa o rentismo e a financeirização, em meio à crise estrutural, é possível sinalizar o seguinte: a) o caráter desigual das condições dadas nesta sociabilidade se acirra, com corte regional, dificultando, inclusive, "[...] ganhos defensivos - normalmente bem acomodados nas margens do lucro em expansão"; b) há uma (re) combinação entre formas de exploração da força de trabalho através, 


\section{temporollis}

inclusive, de mecanismos que viabilizem uma "contínua extorsão de mais-valia absoluta", aprofundando a divisão internacional e regional do trabalho. Isto tendo em vista que "[...] a exploração neocolonial, muito protegida pela extração de mais-valia absoluta, serve perfeitamente aos interesses do 'capital metropolitano' e seu apetite insaciável por superlucros facilmente repatriáveis.” (MEZSÁROS, 2002, p. 682-683).

Tudo isso nos diz que há possibilidades históricas para "contra tendências", para uma súbita e conjuntural melhora nos índices de crescimento econômico, combinada a uma reorganização dos mecanismos de exploração da força de trabalho com maior presença (em relação a outros períodos históricos) da extração de mais-valia relativa, em países e regiões específicas - o que alguns podem até fazer referência aos anos 2000 no Brasil. Porém, tais aspectos não condizem com mudanças estruturais, muito menos duradouras. Ao contrário, (sobre)vivem em meio a constantes crises. Desse entendimento, situamos as interferências mais atuais nas desigualdades regionais presentes na própria formação brasileira.

Assim, para entender o papel e as condições de inserção da região Nordeste no atual projeto de desenvolvimento, é fundamental relacionar os aspectos de "natureza" conjuntural (o valor da força de trabalho, os custos de vida, os incentivos fiscais, a "geografia econômica”, o índice de empregabilidade, o acesso a serviços sociais, etc.) com as condições estruturais, as leis e tendências gerais do capitalismo (em meio ao complexo sistema de financeirização e fetichismo do capital) que, na sua dinâmica "desigual e combinada", permite o crescimento econômico de algumas regiões e a estagnação de outras, pois "[...] o capitalismo ao se desenvolver não resolve as suas contradições. Ao contrário, cria novas" (GRABOIS, 2014, online).

Essa dinâmica, vale ressaltar, é impulsionada não apenas pelos condicionantes e determinantes econômicos, mas também pelas circunstâncias e desdobramentos no âmbito político que põem em outro patamar a luta de classes. Esta, sendo universal é também regionalizada, segundo Harvey (2013). Daí a necessidade em observar que esse movimento de "[...] expansão - estagnação produz clivagens nas classes dominantes [...] que transcendem uma eventual dicotomia esfera financeira $x$ esfera produtiva do capital [... ] as duas esferas são inseparáveis, ainda mais em tempos de predomínio do capital financeiro." (GRABOIS, 2014, online). Isto, mesmo que não se configure 
de forma homogênea nos países, levando em consideração a existências das frações de classes e as diferenciações conjunturais no âmbito econômico que incidem nas alianças políticas e na relação entre as forças sociais.

Sobre isso, dada a heterogeneidade das classes (e de suas frações), a contradição entre regiões que vivenciam um ciclo de expansão e as que presenciam o momento de estagnação implica em uma série de disputas de interesses "inter e intraclasse" que a mera polarização entre "[...] indústria versus interesses financeiros não dá conta da totalidade do conflito de frações da burguesia brasileira. Há industriais que se sentem prejudicados pelo governo federal e banqueiros que se sentem beneficiados." (GRABOIS, 2014, online). Daí a importância em considerar a dimensão regional na análise sobre a realidade.

É nesse contexto que se insere nos últimos anos o Nordeste brasileiro no "movimento mundial articulador de territórios" que não pode ser desconsiderado. Região em que é possível constatar a presença de novos vetores de expansão econômica, porém mantém taxas que revelam desigualdades sociais bem superiores aos índices nacionais. Vale ressaltar, inclusive, as desigualdades históricas e continuamente vivas dentro da própria região, do litoral ao sertão semiárido. "Essa combinação de crescimento econômico, desigualdade social e concentração de atividades dinâmicas em determinadas parcelas do território representa uma configuração sócio espacial", recorrente no desenvolvimento capitalista em outras regiões do mundo (PEREIRA JR., 2012, p. 225). Resta saber se, no Nordeste, assim como no Brasil, esse contexto pode oferecer condições mais favoráveis, do ponto de vista da luta de classes, para os(as) trabalhadores(as).

A finalização deste artigo sinaliza o quanto extenso ainda é o caminho para conhecermos a fundo a complexa e, em muitos aspectos, recente realidade priorizada por nós. Eis, portanto, um dos passos dentre os que já foram dados e outros tantos que virão.

\section{Referências}

ALVES, G. Neodesenvolvimentismo e precarização do trabalho no Brasil (parte I). 2013. Disponível em: <http://blogdaboitempo.com. $\mathrm{br} / 2013 / 05 / 20 /$ neodesenvolvimentismo-e-precarizacao-do-trabalho- 


\section{tempordilis}

no-brasil-parte-i/>. Acesso em: 2 mai. 2015.

ARAÚJO, T. B. de. Desenvolvimento regional brasileiro e políticas públicas federais no governo Lula. In: SADER, Emir (org.). 10 anos de governos pós-neoliberais no Brasil: Lula e Dilma. São Paulo: Boitempo; Rio de Janeiro: FLACSO Brasil, 2013.

ARCARY, V. Um reformismo quase sem reformas: uma crítica marxista do governo Lula em defesa da revolução brasileira. 2. ed. São Paulo: Ed. José Luis e Rosa Sundermann, 2014.

BEHRING, E. R. Brasil em contra-reforma: desestruturação do estado e perda de direitos. São Paulo: Cortez, 2008.

BOITO JR., A. As bases políticas do neodesenvolvimentismo. 2012. Disponível em:<http://eesp.fgv.br/sites/eesp.fgv.br/files/file/Painel\%20 3\%20-\%20Novo\%20Desenv\%20BR\%20-\%20Boito\%20-\%20Bases\%20Pol\%20 Neodesenv\%20-\%20PAPER.pdf_>. Acesso em: 20 mai. 2013.

BRAGA, R. A política do precariado: do populismo à hegemonia lulista. São Paulo: Boitempo, 2012.

CASTELO, R. O novo desenvolvimentismo e a decadência ideológica do pensamento econômico brasileiro. Serviço Social \& Sociedade, São Paulo n.112, p. 613-636, out/dez. 2012.

CHESNAIS, F. A mundialização do capital. São Paulo: Xamã, 1996.

DIEESE. Departamento Intersindical de Estatística e Estudos Socioeconômicos. Estudos e Pesquisas: balanço das greves em 2012. DIEESE, São Paulo, n. 66, maio de 2013.

FATORELLI, M. L.; ÁVILA, R. Os números da dívida. Disponível em: < www.auditoriacidada.org.br/wp-content/uploads/2012/04/Numerosdivida.pdf> Acesso em: 15 set. 2015.

FERNANDES, F. A revolução burguesa no Brasil: ensaio de interpretação sociológica. 5.ed. São Paulo: Globo, 2006.

FERREIRA, R. O mandato é do capital. Brasil de Fato, São Paulo, 9 jan. 2014. Disponível em: < http://www.brasildefato.com.br/node/27033> Acesso em: 17 set. 2015 . 
GORENDER, J. A burguesia brasileira. São Paulo: Brasiliense,1982. (Coleção Tudo é História).

GRABOIS, I. Classes e frações de classe no segundo Governo Dilma. 2014. Disponível em: < http://marxismo21.org/wp-content/ uploads/2014/11/Classes-fra\%C3\%A7\%C3\%B5es-no-segundo-governo-Dilma-I-Grabois.pdf>. Acesso em: 10 abr. 2015.

GRAMSCl, A. Cadernos do cárcere. 3.ed. Rio de Janeiro: Civilização Brasileira, 2006. V.1.

GRANEMANN, S. Políticas sociais e financeirização dos direitos do trabalho. Em Pauta, Rio de Janeiro, n. 20, p.57-68, 2007.

HARVEY, D. Os limites do capital. São Paulo: Boitempo, 2013.

IAMAMOTO, M. O Serviço Social na Contemporaneidade: trabalho e formação profissional. 2. ed. São Paulo: Cortez, 2004.

. Serviço Social em tempo de capital fetiche: capital financeiro, trabalho e questão social. São Paulo: Cortez, 2007.

IANNI, O. Pensamento social no Brasil. São Paulo: EDUSC, 2004.

IBGE. Instituto Brasileira de Geografia e Estatística. Pesquisa Nacional por Amostra de Domicílios. Síntese de indicadores 2012. Disponível em: <http://www.ibge.gov.br/home/estatistica/pesquisas/pesquisa_ resultados.php?id_pesquisa=40>. Acesso em: 12 nov. 2014 .

IPEA. Instituto de Pesquisa Econômica e Aplicada. Brasil em desenvolvimento: estado, planejamento e políticas públicas. Brasília: IPEA, 2010. v. 3 Disponível em:< http://www.ipea.gov.br/bd/pdf/Livro_BD_ vol3.pdf>. Acesso em: 29 jul. 2014.

LOWY, M. Teoria do desenvolvimento desigual e combinado. Revista Actuel Marx, Paris, n. 18, p.73-80, 1995.

LUKÁCS, G. Socialismo e democratização: escritos políticos 1956-1971. Rio de Janeiro: Editora UFRJ, 2008.

MANDEL, E. O capitalismo tardio. São Paulo: Abril Cultural, 1982 (Os economistas) 


\section{temporollis}

MARX, K. O capital: crítica da economia política. São Paulo: Abril Cultural, 1983. Livro 3, Tomo I. (Os economistas)

; ENGELS, F. O manifesto do partido comunista. Rio de Janeiro: Contraponto; São Paulo: Fundação Perseu Abramo, 1998.

- Contribuição à crítica da economia política. São Paulo: Expressão Popular, 2008.

MÉSZÁROS, I. Para além do capital. São Paulo: Boitempo, 2002.

MOTA, A. E. Redução da pobreza e aumento da desigualdade: um desafio teórico-político ao Serviço Social brasileiro. In: . (Org.). Desenvolvimestismo e construção de hegemonia: crescimento econômico e reprodução da desigualdade. São Paulo: Cortez, 2012.

NITAHARA, A. Maior proporção de empresas de alto crescimento está no Norte e Nordeste. Agência Brasil, Rio de Janeiro, 12 dez. 2014. Disponível em: <http://agenciabrasil.ebc.com.br/economia/ noticia/2014-12/emb-maior-proporcao-de-empresas-de-altocrescimento-esta-no-norte-e>. Acesso em: 10 set. 2015.

OLIVEIRA, F. de. Elegia para uma re(li)gião: Sudene, Nordeste: planejamento e conflitos de classes. 3. ed. Rio de Janeiro: Paz e Terra, 1981.

. Crítica a razão dualista. São Paulo: Boitempo, 2013.

OLIVEIRA, N. Região Nordeste registra maior taxa de desocupação do país, diz IBGE. Agência Brasil, Rio de Janeiro, 7 mai. 2015. Disponível em: <http://agenciabrasil.ebc.com.br/economia/noticia/2015-05/ regiao-nordeste-registra-maior-taxa-de-desocupacao-do-pais-diz-ibge >. Acesso em: 03 abr. 2015.

ONUBR. Nações Unidas no Brasil. Mundo tem 232 milhões de migrantes internacionais, calcula ONU. Set. 2013. Disponível em: <https:// nacoesunidas.org/mundo-tem-232-milhoes-de-migrantes-internacionais-calcula-onu/> Acesso em: 12 set. 2015.

OSAVA, M. Preconceito, eleições e a dicotomia na geografia econômica. Jornal Brasil de Fato, São Paulo, 10 nov. 2014. Disponível em: <http://brasildefato.com.br/node/30470_>. Acesso em: 13 abr. 2015. 
PAULO NETTO, J. Desigualdade, pobreza e serviço social. Em Pauta, Rio de Janeiro, n. 19, p. 135-170, 2007.

. Introdução ao método na teoria social. São Paulo: Expressão Popular, 2011.

PEREIRA, E. M.; HOLANDA, D. A. S.; SOARES, R. O. et al. Educação, "neodesenvolvimentismo" e Serviço Social: os IFs em questão. Serviço Social \& Sociedade, São Paulo, n. 122, p. 317-340, abr.jun. 2015.

PEREIRA JUNIOR, E Território e economia política: uma abordagem a partir do novo processo de industrialização no Ceará. São Paulo: Cultura Acadêmica, 2012.

PNUD. Programa das Nações Unidas para o Desenvolvimento. Atlas do desenvolvimento humano no Brasil. 2013. Disponível em:<http:// www.onu.org.br/onu-atlas-brasil-2013-mostra-reducao-de-disparidades-entre-norte-e-sul-nas-ultimas-duas-decadas/>. Acesso em: 26 jul. 2014.

POCHMANN, M. Políticas públicas e situação social na primeira década do século XXI. In: SADER, Emir (Org.). 10 anos de governos pósneoliberais no Brasil: Lula e Dilma. São Paulo: Boitempo; Rio de Janeiro: FLACSO Brasil, 2013.

PORTO, G. Nordeste lidera crescimento no país, segundo BC. Agência Estado, São Paulo, 7 jun. 2013. Disponível em: <http://exame.abril. com.br/economia/noticias/nordeste-lidera-crescimento-no-pais-segundobc>. Acesso em: 30 jul. 2014.

PRADO JR, C. Formação do Brasil contemporâneo. São Paulo: Brasiliense, 2008.

SALLOWICZ, M. Esperança de vida cresce mais no Nordeste que no resto do Brasil. Folha de São Paulo, São Paulo, 2 ago. 2013. Disponível em: <http://www1.folha.uol.com.br/cotidiano/2013/08/1320392-esperanca-de-vida-cresce-mais-no-nordeste-que-no-resto-do-brasil.shtml >. Acesso em: 30 jul. 2014.

TINEO, V. Ainda existem dois Brasis, afirma diretor do IPEA. Jornal Brasil de Fato, São Paulo, 2 set. 2015. Disponível em: <http://www.brasildefato.com.br/node/32843>. Acesso em: 10 set. 2015. 


\section{temporolis}

TROTSKY, L. A história da revolução russa. 2. ed. Rio de Janeiro: Paz e Terra, 1977.

VILLELA, D. Nordeste cresce acima da média do país. O Estado de São Paulo, São Paulo, 23 set. 2013. Disponível em: <http://economia. estadao.com.br/noticias/geral,nordeste-cresce-acima-da-media-do-pais,165312e>. Acesso em: 10 set. 2015.

WACQUANT, L. Punir os pobres: a nova gestão da pobreza nos Estados Unidos. Rio de Janeiro: REVAN/Instituto Carioca de Criminologia, 2013. 